\title{
KONTRIBUSI BURUH PEREMPUAN TERHADAP PENDAPATAN KELUARGA (STUDI KASUS TEMPAT PELELANGAN IKAN DI TUMUMPA KOTA MANADO)
}

\author{
Jilly B.C. Sinadia \\ Welson M. Wangke \\ Noortje M. Benu
}

\begin{abstract}
ABSRACT
Problems in research is needs economy of a family the average at the Tumumpa II not enough because the head of the household income is relatively low, so as to meet the needs of a family housewieves at the Tumumpa II trying to provided for by working as woman. Research aims to understand how much contribution given by women who work as a fish. Research carried out in October until December 2016. The data of this research were primary and secondary data. The primary data was obtained through interviews directly to 46 respondents using kuisoner and secondary data obtained from office fisheries and marine and the village office Tumumpa II. The sample technique is purposive sampling the techniques with based on criteria respondents were women who own husband or and married wit responsibility for in the family. Data generated presented in the form of table and described the contribution given by workers women. To know the contribution given by workers women obtained from the percentage of income husband and wife and the son (who have worked). The result showed that woman sho worked as labarers carrying fish contributed for 44,90\%. This means that the contribution of income of family income at the Tumumpa II big enough, what is mean by big enough is on the income female by working as laborers have been very helpful husband by meet and sufficient need in housholds every day.
\end{abstract}

Keywords: contribution, workers, women, income, family, Manado City.

\begin{abstract}
ABSTRAK
Kebutuhan ekonomi keluarga rata-rata di Kelurahan Tumumpa II belum tercukupi karena pendapatan kepala keluarga relatif rendah, sehingga untuk memenuhi kebutuhan keluarga ibu rumah tangga di Kelurahan tumumpa II berusaha mencukupi kebutuhan dengan bekerja sebagai buruh perempuan. Penelitian bertujuan untuk mengetahui berapa besar kontribusi yang diberikan oleh perempuan yang bekerja sebagai buruh. Penelitian dilaksanakan pada bulan Oktober sampai Desember 2016. Pengambilan data berupa data primer dan data sekunder. Data primer diperoleh melalui wawancara langsung kepada 46 responden dengan menggunakan kuisoner dan data sekunder diperoleh dari Dinas Perikanan dan Kelautan, Kantor Kelurahan Tumumpa II. Teknik pengambilan sampel adalah Purposive Sampling yaitu teknik dengan mempertimbangkan kriteria responden adalah perempuan yang bekerja sebagai buruh, masih memiliki suami dan berstatus menikah dan memiliki tanggungan dalam keluarga . Data yang dihasilkan disajikan dalam bentuk tabel dan di analisis secara deskriptif untuk mendeskripsikan dan menggambarkan besarnya kontribusi yang diberikan oleh buruh perempuan. Untuk mengetahui besarnya kontribusi yang diberikan oleh buruh perempuan diperoleh dari persentase antara pendapatan istri, pendapatan suami dan juga anak (yang sudah bekerja). Hasil penelitian menunjukan bahwa persentase perempuan yang bekerja sebagai buruh memberikan kontribusi sebesar 44,90\%. Kontribusi buruh perempuan sebesar 44,90\% Ini artinya bahwa kontribusi pendapatan perempuan terhadap pendapatan keluarga di Kelurahan Tumumpa II baik, yang di maksud dengan baik adalah dengan pendapatan yang diperoleh perempuan dengan bekerja sebagai buruh sudah sangat membantu suami dalam memenuhi dan mencukupkan kebetuhan dalam rumah tangga setiap hari. Sehingga bila tanpa kontribusi dari perempuan, maka kebutuhan dalam keluarga belum dapat tercukupi.
\end{abstract}

Kata kunci: kontribusi, buruh, perempuan, pendapatan, keluarga, Kota Manado. 


\section{PENDAHULUAN}

\section{Latar Belakang}

Perkembangan pembangunan yang semakin hari semakin berkembang dengan cepat telah membuka kesempatan bagi perempuan yang ingin bekerja. Saat ini pekerja perempuan sudah semakin terlihat dengan jelas di berbagai bidang pekerjaan. Sejak menyadari bahwa perempuan juga bisa memberikan kontribusi dalam keluarga pemerintah Indonesia memasukkan kebijakan untuk perempuan yang dikenal dengan kebijakan peran ganda. Kebijakan ini didasarkan pada asumsi bahwa selama ini kaum perempuan karena "hanya" berperan sebagai istri dan ibu dianggap tidak dapat memberikan kontribusi apapun dalam pembangunan. Oleh karenanya perempuan didorong untuk berpartisipasi aktif di sektor publik dan memberikan kontribusi dalam keluarga, sekaligus tetap harus menjalankan fungsinya sebagai istri dan ibu (Nursyahbani dalam Handayani \& Putu Artini2009). Kontribusi adalah keikutsertaan, keterlibatan, melibatkan diri maupun sumbangan. Dalam hal ini kontribusi tidak hanya berupa tindakan saja melainkan berupa materi. Dengan berkontribusi berarti individu berupaya untuk meningkatkan kehidupannya (Puspitasari, Puspitawati dan Herawati 2013). Berdasarkan aspek ekonomi keluarga, keterlibatan perempuan dalam ketenagakerjaan mempunyai arti tersendiri dalam kehidupan, baik sebagai individu, isteri, ibu rumah tangga maupun sebagai anggota masyarakat (Momuat, 2012).

Keterlibatan perempuan dalam areal publik sebagai seorang pencari nafkah dilakukan karena keadaan perekonomian keluarga yang semakin berkekurangan, hidup dan tinggal di perkotaan dengan jumlah anggota keluarga yang menjadi tanggungan serta pendapatan suami yang semakin tidak menentu, keadaan suami yang sakit atau mengalami kecelakaan membuat perempuan harus berperan ganda dan berkontribusi dengan nyata dalam perekonomian keluarga. Kesempatan untuk membantu suami dan berkontribusi secara langsung dalam ekonomi keluarga para perempuan ini memutuskan menjadi buruh lepas di tempat pelelangan ikan di Kelurahan Tumumpa II. Kelurahan Tumumpa II yang ada di Kecamatan Tuminting Kota Manado adalah salah satu tempat pemukiman yang mata pencahariannya nelayan, bertani dan berdagang dan juga melakukan jasa msyarakat lainnya. Di Kelurahan Tumumpa II adalah salah satu tempat pelabuhan perikanan pantai atau yang lebih dikenal dengan tempat pelelangan ikan. Aktivitas setiap hari adalah bertemunya nelayan dan pembeli ikan.

Bekerja sebagai buruh lepas, dilakukan pada setiap kesempatan untuk memanfaatkan waktu yang tersisa setelah melakukan pekerjaan rumah tangga. Kegiatan bekerja sebagai buruh lepas sangat terlihat jelas di sore hari, karena pada umumnya kapal yang beroperasi waktu hari dan akan masuk pelabuhan di sore hari dengan variasi waktu yang tidak menentu untuk setiap kapal tetapi aktivitas dipelabuhan mulai terlihat dengan jelas kurang lebih pukul 14.00 (wita) sore. Buruh perempuan yang bekerja sudah mengetahui dengan jelas kapan kapal akan masuk. Ketika kapal sudah masuk pelabuhan para buruh perempuan sudah bersiap dengan perlengkapan masing-masing dan mulai naik ke kapal membantu laki-laki untuk membongkar ikan. Kegiatan pembongkaran ini sangat dibutuhkan tenaga perempuan, sementara melakukan kegiatan pembongkaran ikan sebagian perempuan sudah menyiapkan keranjang untuk memilih atau menyortir ikan, karena pembongkaran ikan yang dilakukan pasti akan ada ikan yang lecet sehingga memilih atau menyortir ikan diperlukan agar bisa diperoleh ikan yang layak untuk dipasarkan. Sementara memilih ikan sebagian perempuan membawa air bersih (menggunakan selang) untuk mencuci ikan dan kemudian sebagian perempuan yang sudah siap akan mengangkut ikan dengan menggunakan media/alat yaitu ember dan keranjang dengan jarak angkat dari kapal ke tempat pelelangan ikan \pm 10 meter. Lamanya kegiatan bekerja sebagai buruh lepas dilakukan sesuai jumlah ikan yang ada, dan setiap buruh perempuan sudah menentukan di bagian apa saja dia akan bekerja. Setiap kapal sudah memiliki pembeli ikan atau pelanggan tetap sehingga buruh perempuan sudah mengetahui dengan jelas ikan yang diangkut dibawa kepada pembeli atau pelanggan tetap yang ada di tempat pelelangan ikan.

Setiap buruh perempuan sudah memiliki lokasi kapal masing-masing sehingga setiap orangnya hanya bekerja pada satu kapal dan sistim upah yang didapat diberikan langsung oleh pemilik kapal. Upah yang didapatkan relatif sesuai dengan jumlah ikan yang ada, jika ikan 
yang diperoleh banyak upah yang akan didapatkan besar tetapi jika ikan yang diperoleh hanya sedikit upah yang didapatkan kecil tapi pada umumnya upah yang diperoleh buruh perempuan sebesar Rp 100.000,-. Selain sebagai ibu rumah tangga, buruh lepas ada juga dari sebagian perempuan bekerja sebagai buruh tani. Hasil yang didapat dengan bekerja sebagai buruh lepas digunakan untuk keperluan setiap hari, dengan pendapatan yang diperoleh perempuan yang bekerja sebagai buruh telah memberikan kontribusi yang nyata dalam pendapatan keluarga. Perempuan yang bekerja sebagai buruh lepas sebagian besar berasal dari warga lokal (warga setempat) dan ada juga yang berasal dari Kelurahan yang berbeda seperti Kelurahan Bailang, Kelurahan Tiwoho dan kelurahan yang lainnya. Kontribusi ekonomi perempuan terhadap keluarga akan berdampak positif dalam keluarga karena dengan kontribusi yang diberikan akan meningkatkan ekonomi keluarga (Puspitasari dkk, 2013). Berdasarkan fenomena inilah maka peneliti tertarik ingin mengetahui berapa besar kontribusi buruh perempuan terhadap pendapatan keluarga.

\section{Rumusan Masalah}

Kebutuhan ekonomi keluarga rata-rata di Kelurahan Tumumpa II belum tercukupi karena pendapatan kepala rumah keluarga relatif rendah, sehingga untuk memenuhi kebutuhan keluarga ibu rumah tangga di Kelurahan tumumpa II berusaha mencukupi kebutuhan dengan bekerja sebagai buruh perempuan. Berdasarkan latar belakang yang menjadi rumusan permasalahan dalam penelitian ini adalah seberapa besar kontribusi yang diberikan oleh buruh perempuan terhadap pendapatan keluarga dengan studi kasus Tempat Pelelangan Ikan di Tumumpa Kota Manado.

\section{Tujuan Penelitian}

Penelitian ini bertujuan untuk mengetahui berapa persen kontribusi pendapatan buruh perempuan terhadap pendapatan keluarga.

\section{Manfaat Penelitian}

Melalui penelitian ini diharapkan dapat bermanfaat untuk peneliti terutama dalam penerapan ilmu yang dipelajari dan sebagai bahan referensi bagi para pemerhati tentang studi pekerja perempuaan.

\section{METODOLOGI PENELITIAN}

\section{Waktu dan Tempat Penelitian}

Penelitian ini dilaksanakan ditempat pelelangan ikan yang ada di Kelurahan Tumumpa II Kecamatan Tuminting Kota Manado. Penelitian ini dilaksankan selama empat bulan dari bulan November 2016 sampai dengan Februari 2017.

\section{Metode Penelitian}

Metode yang digunakan dalam penelitian ini adalah bentuk penelitian yang mendeskripsikan semua kejadian dan peristiwa, perilaku orang dan suatu keadaan pada tempat tertentu. Yang di maksud peneiliti disini adalah keseluruhan kegiatan perempuan yang bekerja sebagai buruh, dan kedaan di tempat pelelangan ikan secara rinci, factual dan akurat secara sitematis dan mendalam dalam bentuk narasi. Bahan-bahan ini hanya dapat digolongkan dalam bentuk kategori-kategori. Kategori-kategori yang dimaksud dalam penelitian ini yaitu seberapa besar kontribusi yang secara langsung diberikan oleh pekerja perempuan terhadap pendapatan keluarga.

\section{Metode Pengumpulan Data}

Data yang dikumpulkan adalah data primer dan sekunder. Data primer diperoleh dari wawancara langsung dengan responden berdasarkan daftar pertanyaan yang telah disiapkan dengan menggunakan kuisoner bagi responden buruh perempuan di Tempat Pelelangan Ikan di Tumumpa Kota Manado. Data sekunder diperoleh dari Dinas Perikanan dan Kelautan, Kantor Kelurahan Tumumpa II dan literatur-literatur yang berhubungan dengan penelitian.

\section{Metode Pengambilan Sampel}

Pengambilan sampel menggunakan metode Purposive Sampling yaitu pengambilan data atau responden yang dilakukan secara sengaja dengan mempertimbangkan kriteria responden yang menjadi sampel adalah mereka yang bekerja sebagai buruh perempuan, yang sudah menikah dan masih memiliki suami, dan memiliki tanggungan anggota keluarga. Dalam penelitian ini banyaknya sampel yang diambil 
adalah 46 buruh di Tempat Pelelangan Ikan Tumumpa.

\section{Konsep Pengukuran Variabel}

\section{Indikator Responden}

a. Jenis Kelamin: Perempuan

b.Umur responden adalah usia yang dimiliki oleh responden (tahun)

c.Pendidikan responden adalah lamanya responden mengenyam pendidikan

d. Jumlah Tanggungan Keluarga adalah total keseluruhan anggota keluarga

e. Alasan Bekerja yaitu dorongan yang timbul dan membuat keputusan

f. Curahan waktu kerja porposi waktu yang diberikan selama bekerja

\section{Variable yang digunakan dalam penelitian ini terdiri atas:}

a. Pendapatan buruh perempuan adalah total pendapatan yang sudah dikurangi dengan biaya yang dikeluarkan selama satu bulan (Rp/bula

b. Pendapatan Keluarga adalah total keseluruhan pendapatan suami, isteri dan anak yang sudah dikurangi dengan biaya yang dikeluarkan selama satu bulan (Rp/bulan)

c.Kontribusi Pendapatan Buruh perempuan adalah keseluruhan pendapatan yang diperoleh perempuan dan pendapatan keluarga (\%)

\section{Metode Analisis Data}

Metode analisis data yang di gunakan dalam penelitian ini adalah menggunakan analisis deskriptif dan akan disajikan dalam bentuk tabel, kemudian akan dilanjutkan dengan perhitungan. Untuk mendapatkan dan mengetahui besarnya pendapatan maka digunakan rumus

$$
\mathbf{I}=\mathbf{T R}-\mathbf{T C}
$$

Di mana :

I = Income (Pendapatan Buruh Perempuan)

$\mathrm{TR}=$ Total Revenue (Total Penerimaan Buruh Perempuan)

TC = Total Cost (Total Biaya yang di Keluarkan buruh Perempuan)

Selanjutnya untuk mengetahui besarnya kontribusi buruh perempuan digunakan rumus : indeks share $=\frac{\mathrm{X}_{1} \times 100 \%}{\mathrm{X}_{2}}$

Di mana : $\mathrm{X}_{2}$

Indeks Share $=$ Besaran Kontribusi

$$
\begin{array}{ll}
\mathrm{X}_{1} & =\text { Pendapatan Buruh Perempuan } \\
\mathrm{X}_{2} & =\text { Pendapatan Keluarga } \\
\text { Share (Kontribusi) } & =\frac{\text { Pendapatan Buruh Perempuan }}{\text { Pendapatan Keluarga }} \times 100 \%
\end{array}
$$

Skala Interval Kontribusi

$\begin{array}{cc}\begin{array}{c}\text { Persentase Tingkat } \\ \text { Kontribusi }\end{array} & \text { Kriteria Kontribusi } \\ 0,00-10,00 \% & \text { Sangat Kurang } \\ 10,01-20,00 \% & \text { Kurang } \\ 20,01-30,00 \% & \text { Sedang } \\ 30,01-40,00 \% & \text { Cukup } \\ 41,01-50,00 \% & \text { Baik } \\ >50 \% & \text { Baik Sekali }\end{array}$

Sumber : Zulkifri dkk, 2014

\section{HASIL DAN PEMBAHASAN}

\section{Gambaran Umum Tempat Penelitian}

Kecamatan Tuminting merupakan salah satu dari sebelas kecamatan yang ada di Kota Manado. Kecamatan Tuminting terdiri dari sepuluh Kelurahan yaitu, Kelurahan Maasing, Kelurahan Bitungkarangria, Kelurahan Kampung Islam, Kelurahan Mahawu, Kelurahan Sindulang II, Kelurahan Sindulang I, Kelurahan Sumompo, Kelurahan Tuminting, Kelurahan Tumumpa I, Kelurahan Tumumpa II. Kelurahan Tumumpa II adalah salah satu kelurahan yang ada di Kecamatan Tuminting dengan luas wilayah $186.869 \mathrm{Km}^{2}$ dan berbatasan dengan: Sebelah Utara: Berbatasan dengan Sungai Bailang. Sebelah Selatan: Berbatasan dengan Kelurahan Maasing. Sebelah Timur: Berbatasan dengan Kelurahan Tumumpa Satu. Sebelah Barat: Berbatasan dengan Teluk Manado. Kelurahan Tumumpa II dikenal sebagaai salah satu tempat pelelangan ikan/pelabuhan perikanan yang ada di Kota Manado.Dengan fungsi utama melakukan kegiatan perikanan (Memanfaatkan Sumber Daya Alam) dan usaha untuk menggerakan usaha dan kesejahteraan masyarakat nelayan. Berdasarkan Undang-undang Nomor 31 Tahun 2004 Penjelasan Pasal 41 Ayat 1 bahwa fungsi pelabuhan perikanan adalah :

1) Tempat tambat labuh kapal perikanan

2) Tempat pendaratan ikan

3) Tempat pelelangan, pemasaran dan distribusi ikan

4) Tempat pelaksanaan pembinaan mutu hasil perikanan

5) Tempat pengumpulan data tangkap

6) Tempat pelaksanaan penyuluhan serta pengembangan masyarakat nelayan 
7) Tempat untuk memperlancar kegiatan operasional kapal perikanan.

Soerato dan Hasan Jan (2016) UPTD Balai Pengembangan dan Pembinaan Penangkapan Ikan, Kapal/perahu tangkap ikan yang berpangkalan di pelabuhan ini adalah kapal motor yang berukuran 10-30 GT yang berjumlah 73 unit kapal. Kapal-kapal ini merupakan kapal yang berstatus pemilikan perorangan (nelayan pemilik) yang mempekerjakan beberapa pekerja (nelayan penggarap) didalamnya. Zona penangkapan ikan dari kapal-kapal di Tempat Pelelangan Ikan ini meliputi perairan laut Sulawesi dan laut Maluku. Tempat Pelelanga Ikan Tumumpa merupakan pelabuhan yang produktif, dengan kata lain setiap hari selalu ada aktivitas keluar masuk kapal penangkapan ikan. Letak geografis tempat pelelangan ikan (TPI) 1'31'21'"LU dan $124^{\circ} 50^{\prime} 28^{\prime \prime}$ BT dengan luas lahan $4 \mathrm{Ha}$ dengan jarak dari Ibu Kota Provinsi $3 \mathrm{~km}$, tempat pelelangan ikan (TPI) mulai dibangun pada tahun 1993/1994 dan mulai melakukan operasi pada tahun 2002 dengan status pelabuhan awal sebagai Pangkalan Pendaratan Ikan (Tipe D) dan sekarang telah menjadi status Pelabuhan Perikanan Pantai sesuai dengan Kepmen KP Nomor 10/Men/2005. Produksi perikanan hasil tangkap ada 5 jenis ikan yang unggul ditempat pelelangan ikan yaitu ikan cakalang $10.726 .608 \mathrm{~kg} / \mathrm{hari}$, ikan tongkol $1.720 .410 \mathrm{~kg} / \mathrm{hari}$, ikan baby tuna 1.239 .860 $\mathrm{kg} / \mathrm{hari}$, ikan laying $1.562 .225 \mathrm{~kg} / \mathrm{hari}$, ikan selar $10.125 \mathrm{~kg} /$ hari dengan total $15.246 .618 \mathrm{~kg}$ atau 42 Ton/hari.

\section{Deskripsi Buruh Perempuan}

Buruh perempuan adalah sebagian ibu rumah tangga yang bekerja sebagai buruh lepas di tempat pelelangan ikan di Tumumpa Kota Manado. Perempuan yang bekerja sebagai buruh mempunyai alasan yaitu ingin membantu suami menstabilkan perekonomian dalam keluarga, tidak selesai sekolah, banyaknya anggota tanggungan dalam keluarga, ingin mengambangakan diri dan mengikuti lingkungan kehidupan (mengikuti teman dan saudara). Dengan bekerja sebagai buruh lepas setiap harinya perempuan terlebih dahulu melakukan pekerjaan rumah tangga dan setelah itu bekerja sebagai buruh. Curahan waktu adalah porposi waktu yang diberikan selama bekerja. Dan waktu yang diberikan adalah 4,3 jam setiap hari, curahan waktu yang diberikan oleh buruh perempuan selama bekerja tidak besar sehingga tidak mempengaruhi pekerjaan rumah tangga. Sebagian besar buruh perempuan memiliki pendidikan yang rendah SD sampai dengan SMP.

\section{Karakteristik Responden Menurut Umur} Tingkat umur mempengaruhi kemampuan seseorang dalam melakukan aktifitas maupun konsep berpikir seseorang, dalam penelitian ini yaitu buruh wanita. Buruh perempuan yang memiliki umur lebih muda tentunya memiliki kondisi fisik yang lebih kuat. Dan sebaliknya buruh perempuan yang berumur tua lebih menjaga kesehatannya. Dari data primer yang diperoleh, jumlah responden berdasarkan umur dapat di lihat pada Tabel 2.

Tabel 2. Karakteristik Responden Menurut Umur

\begin{tabular}{lccc}
\hline No & $\begin{array}{c}\text { Umur } \\
\text { (Tahun) }\end{array}$ & $\begin{array}{c}\text { Jumlah Responden } \\
\text { (Orang) }\end{array}$ & $\begin{array}{c}\text { Presentase } \\
(\%)\end{array}$ \\
1 & $21-30$ & 13 & $28,26 \%$ \\
2 & $31-40$ & 18 & $39,14 \%$ \\
3 & $41-50$ & 12 & $26,08 \%$ \\
4 & $>50$ & 3 & $6,52 \%$ \\
\hline & Total & 46 & $100 \%$ \\
\hline
\end{tabular}

Sumber : Data Primer, diolah 2017

Berdasarkan Tabel 2 menunjukkan bahwa responden yang berumur 31 hingga 40 tahun jumlahnya sebanyak 18 orang $(39,14 \%)$. Responden yang berumur 21 hingga 30 tahun jumlahnya sebanyak 13 orang $(28,26 \%)$. Responden yang berumur 41 hingga 50 tahun jumlahnya 12 orang $(26,08 \%)$ Sedangkan responden yang berumur lebih dari 51 tahun sebanyak 3 orang $(6,52 \%)$. Hal inimenunjukkan bahwa perempuan yang bekerja sebagai buruh berada pada usia produktif, yaitu berumur 31 tahun hingga 40 tahun sebanyak 18 orang $(39,14 \%)$.

\section{Karakteristik Responden Menurut Pendidikan}

Semakin tinggi tingkat pendidikan seseorang semakin banyak pengetahuan dan wawasan yang dimiliki. Pendidikan dapat menentukan seseorang bisa bekerja sesuai dengan kemampuan yang dimiliki. Dari hasil penelitian yang dilakukan tingkat pendidikan responden dapat dilihat pada tabel 3 . 
Tabel 3. Karakteristik Responden Menurut Pendidikan

\begin{tabular}{cccc}
\hline No & $\begin{array}{c}\text { Tingkat } \\
\text { Pendidikan }\end{array}$ & $\begin{array}{c}\text { Jumlah } \\
\text { Responden } \\
\text { (Orang) }\end{array}$ & $\begin{array}{c}\text { Persentase } \\
\%\end{array}$ \\
1 & $\begin{array}{c}\text { Tidak } \\
\text { Sekolah }\end{array}$ & 7 & $15,21 \%$ \\
2 & SD & 15 & $32,60 \%$ \\
3 & SMP & 8 & $34,80 \%$ \\
4 & SMA & 46 & $17,39 \%$ \\
\hline
\end{tabular}

Sumber : Data Primer, diolah 2017

Tabel 3 menunjukkan bahwa responden yang tidak sekolah sebanyak 7 orang $(15,21 \%)$. Responden yang berpendidikan SD sebanyak 15 orang $(32,60 \%)$, kemudian responden yang berpendidikan SMP sebanyak 16 orang $(34,80 \%)$ dan responden yang berpendidikan SMA sebanyak 18 orang $(7,391 \%)$. Hal ini menunjukkan buruh perempuan sebagian besar masih berpendidikan rendah yaitu tamatan SD dan SMP sebanyak 31 orang $(67,4 \%)$.

\section{Karakteristik Responden Menurut Tanggungan Keluarga}

Tanggungan kelurga adalah jumlah anggota keluarga meliputi suami, isteri dan anak-anak yang menjadi beban tanggungan dalam keluarga.Dari hasil data jumlah tanggungan keluarga bisa dilihat pada Tabel 4.

\section{Tabel 4. Karakteristik Responden Tanggungan} Keluarga

\begin{tabular}{cccc}
\hline Ko & $\begin{array}{c}\text { Tanggungan } \\
\text { Keluarga }\end{array}$ & $\begin{array}{c}\text { Jumlah } \\
\text { Responden } \\
\text { (Orang) }\end{array}$ & $\begin{array}{c}\text { Persentase } \\
\%\end{array}$ \\
1 & 1 & 9 & $19,56 \%$ \\
2 & 2 & 15 & $32,60 \%$ \\
3 & 3 & 13 & $28,26 \%$ \\
4 & 4 & 6 & $13,04 \%$ \\
5 & 5 & 3 & $6,54 \%$ \\
\hline & Total & 46 & 100 \\
\hline
\end{tabular}

Sumber : Data Primer, diolah 2017

Tabel 4 memperlihatkan bahwa responden buruh perempuan memiliki jumlah tanggungan 2 orang sebesar 15 responden $(32,60 \%)$. Jumlah responden yang beranggota keluarga 3 orang sebanyak 13 responden $(28,26 \%)$. Jumlah anggota keluarga 1 orang sebanyak 9 responden $(19,56 \%)$. Jumlah tanggungan 4 orang sebanyak 6 responden $(13,04 \%)$ dan jumlah tanggungan 5 orang sebanyak 3 responden $(6,54 \%)$. Hal ini menunjukan bahwa jumlah tanggungan keluarga mempengarahui responden untuk memilih membantu suami bekerja.

\section{Pendapatan Buruh Perempuan}

Pendapatan buruh perempuan adalah pendapatan yang diterima langsung setelah bekerja. Pendapatan ini adalah pendapatan bersih yang sudah dikurangi dengan biaya yang dikeluarkan selama bekerja. Dari hasil data pendapatan buruh perempuan bisa dilihat total pendapatan dari 46 buruh perempuan setiap bulan sebesar Rp. 59.950.000,- / bulan dengan rata-rata setiap responden adalah Rp.1.303.260,- /bulan dan dengan range Rp1.250.000,- sampai dengan $\mathrm{Rp}$ 1.500.000,-. Pendapatan ini relatif kecil atau kurang dari UMR yang telah ditetapkan Provinsi Sulawesi Utara, namun buruh perempuan tetap memilih bekerja sebagai buruh. Hal ini karena buruh perempuan menerima upah secara langsung dari pemilik kapal setelah selesai bekerja tanpa harus menunggu sebulan untuk mendapatkan upah sehingga buruh perempuan dapat mencukupi kebutuhan setiap hari selama menunggu upah yang akan didapatkan oleh suami. Buruh perempuan juga menganggap lebih baik bekerja dengan upah rendah daripada tidak bekerja sama sekali agar dapat memberikan kontribusi bagi pendapatan keluarga.

\section{Pendapatan Keluarga}

Pendapatan keluarga adalah pendapatan bersih yang diperoleh dari suami, isteri dan anak yang bekerja selama satu bulan. Dari hasil data pendapatan keluarga bisa dilihat pada Tabel 5

Tabel 5. Pendapatan Keluarga/Bulan

\begin{tabular}{|c|c|c|c|}
\hline No & $\begin{array}{c}\text { Pendapatan Keluarga } \\
(\mathrm{Rp})\end{array}$ & $\begin{array}{c}\text { Jumlah } \\
\text { Responden } \\
\text { (Keluaraga) }\end{array}$ & $\begin{array}{c}\text { Persentas } \\
\text { e }\end{array}$ \\
\hline 1 & Rp. 2.000.000 & 7 & $15,22 \%$ \\
\hline 2 & $\begin{array}{l}\text { Rp. } 2.100 .000- \\
\text { Rp.3.000.000 }\end{array}$ & 24 & $52,17 \%$ \\
\hline 3 & $\begin{array}{l}\text { Rp. } 3.100 .000- \\
\text { Rp. } 4.000 .000\end{array}$ & 13 & $28,26 \%$ \\
\hline \multirow[t]{2}{*}{4} & >Rp. 4.000 .000 & 2 & $4,35 \%$ \\
\hline & Total & 46 & 100 \\
\hline
\end{tabular}

Sumber : Data Primer, diolah 2017 
Tabel 5 menunjukan bahwa pendapatan yang di peroleh keluarga (suami, istri dan anak) sebagian besar pendapatan yang diperoleh keluarga dengan jumlah yang cukup besar adalah 24 keluarga $(52,17 \%)$ yaitu sebesar Rp. 2.100.000 hingga Rp.3.000.000. Selanjutnya 13 keluarga $(28,26 \%)$ memperoleh pendapatan sebesar Rp. 3.100.000 hingga Rp. 4.000.000, selanjutnya 2 keluarga $(4,35 \%)$ memperoleh pendapatan sebesar >Rp. 4.000.000 dan yang relatif kecil adalah 7 keluarga $(15,22 \%)$ memperoleh pendapatan sebesar Rp.2.000.000. Pendapatan keluarga responden merupakan pendapatan bersih yang sudah dikurangi dengan biaya yang diperlukan setiap hari. Dari total 46 keluarga memperoleh pendapatan setiap bulan sebesar Rp.133.500.000,- /bulan dengan rata-rat setiap keluarga memperoleh pendapatan sebesar Rp.2.902.173,- / bulan, dengan range Rp.2.100.000, sampai dengan Rp. 3.000.000,-. Pendapatan keluarga adalah total seluruh pendapatan (Suami, insteri dan anak).

\section{Kontribusi Pendapatan Buruh Perempuan}

Total Pendapatan yang diterima oleh responden dari hasil sebagai tenaga buruh pengangkut ikan dibagi dengan total pendapatan keluaraga dan dikali 100\% dandengan demikian akan terlihat kontribusi pendapatan responden (perempuan) terhadap pendapatan keluraga. Total keseluruhan pendapatan buruh perempuan selama satu bulan sebesar Rp. 59.950.000,dengan rata-rata pendapatan setiap responden sebesar Rp.1.303.260,- / bulan. Total keseluruhan pendapatan keluarga selama satu bulan sebesar Rp. 133.500.000,- dengan ratarata pendapatan setiap keluarga sebesar Rp.2.902.173,- /bulan. Berdasarkan data total pendapatan responden dan pendapatan keluarga maka kontribusi pendapatan buruh perempuan terhadap pendapatan keluarga adalah $44,90 \%$. Ini artinya bahwa kontribusi pendapatan perempuan terhadap pendapatan keluarga baik, yang di maksud dengan baik adalah dengan pendapatan yang diperoleh perempuan dengan bekerja sebagai buruh sudah sangat membantu suami dalam memenuhi dan mencukupkan kebetuhan dalam rumah tangga setiap hari. Sehingga bila tanpa kontribusi dari perempuan, maka kebutuhan dalam keluarga belum dapat tercukupi.

\section{KESIMPULAN DAN SARAN}

\section{Kesimpulan}

Kontribusi buruh perempuan sebesar $44,90 \%$ terhadap keluarga Ini artinya bahwa kontribusi pendapatan perempuan terhadap pendapatan keluarga di Kelurahan Tumumpa II tergolong dalam kategori baik, yang di maksud dengan baik adalah dengan pendapatan yang diperoleh perempuan dengan bekerja sebagai buruh sudah sangat membantu suami dalam memenuhi dan mencukupkan kebetuhan dalam rumah tangga setiap hari. Sehingga bila tanpa kontribusi dari perempuan, maka kebutuhan dalam keluarga belum dapat tercukupi.

\section{Saran}

Untuk meningkatkan kontribusi dalam pendapatan keluarga sebaiknya perempuan bisa lebih memanfaatkan waktu luang ketika tidak melakukan pekerjaan sebagai buruh pengangkut ikan dengan melakukan kegiatan atau usaha yang lain agar bisa menambah pendapatan dan memberikan kontribusi bagi keluarga.

\section{DAFTAR PUSTAKA}

Anonim,(2008).Buruh Perempuan dan Relasi industrial.Women Research Institute

Anonim, (2011).Peranan dan Curahan Kerja Wanita Pesisir Dalam Meningkatkan Pendapatan Rumah Tangga di Daerah Tujuan Wisata..

Arnis, (2000). Peran Wanita Dalam PeningkatanPendapatan Dan Kesejahteraan Rumah Tangga : Studi Kasus Bakul seret di Desa Bendar, Kec Juwana, Kab Pati, Provinsi Jawa Tengah. Skripsi Fakultas Perikanan dan Ilmu Kelautan Institut Pertanian Bogor. 
Handayani, M.Th \& Putu Artini, (2009). "Kontribusi Pedapatan Ibu Rumah Tangga Pembuat Makanan Olahan Terhadap Pendapatan Keluarga", Jurnal Agribisnis Fakultas Pertanian Universitas Udayana.

Hayati, L. (2011). Kontribusi Ekonomi, Peran Ganda Perempuan Dan Kesejahteraan Keluarga Buruh Pabrik (Studi Kasus di Kecamatan Dramaga-Kabupaten Bogor). Skripsi Fakultas Ekologi Manusia Institut Pertanian Bogor.

Ilham Akbar. (2011).Pengaruh Pertumbuhan Ekonomi dan Upah Terhadap Tingkat Partisipasi Angkatan Kerja Wanita Kota Makasar Periode 2000-2009.Skripsi Fakultas Ekonomi Universitas Hasaniddin Makassar.

Kristina,A. (2010). Partisipasi Perempuan Dalam Perbaikan Perekonomian Keluarga dan Masyarakat.Pamator Volume 3 No,1.

Makawekes, N. (2016). Dinamika Kelompok Tani Cempaka di Kelurahan Meras Kecamatan Bunaken Kota Manado. Skripsi Fakultas Pertanian Universitas Sam Ratulangi Manado

Momuat, S.( 2012). Kontribusi Kerja Wanita Dalam Keluarga Petani Aren di Desa Rambunan dan Sawangan Sonder.Skripsi Fakultas Pertanian Universitas Sam Ratulangi Manado.

Munawaroh, M., Wahyunigsi. S \& Awami S.N. (2013)." Kontribusi Buruh Wanita Penyadap Karet Terhadap Pendapatan Keluarga : Studi Kasus di PTPN IX Balong/Beji-Kalitelo Afdelling Ngandong Kabupaten Jepara", Jurnal Agribisnis Fakultas Pertanian Universitas Wahid Hasyim, Vol. 2, No.2 : 36-45.

Mundayat, A., et al. (2008). Balada Buruh Perempuan. Women Research Institute. Jakarta.

Puspitasari, N., Puspitawati, H., \& Herawati, T., (2013). Peran gender, kontribusi ekonomi perempuan dan kesejahteraan keluarga petani holtikultura. Jurnal Ekologi Mansuia Vol. 6, No 1

Rahardjo, et, al., (1986). Wanita Kota Jakarta, Kehidupan Keluarga dan Keluarga Berencana. Gadjah Mada University Press

Rakomole, D., (2015). Peran Wanita Pedagang Sayuran Terhadap Pendapatan Keluarga di Pasar Pinasungkalan Karombasan Manado.Skripsi Fakultas Pertanian Universitas Sam Ratulangi Manado.

Setiawan, S. A., (2010). Pengaruh Umur, Pendidikan, Pendapatan, Pengalaman Kerja dan Jenis Kelamin Terhadap Lamanya Mencari Kerja Bagi Tenaga Kerja Terdidik di Kota Magelang. Skripsi Fakultas Ekonomi Unversitas Dipenogoro Semarang.

Setiadi,\&Kolip., (2010). Pengantar Sosiologi, Pemahaman Fakta dan Gejala Permasalahan Sosial, Teori, Aplikasi dan Pemecahanya. Jakarta

Soeratno,\& Hasan Jan. (2016).“ Analisis Model Supply Chain Cakalang di Kota Manado : Studi Kasus Pada Tempat Pelelangan Ikan Pelabuhan Perikanan Pantai Tumumpa" Jurnal Ekonomi dan Bisnis Universitas Sam Ratulangi Manado, Vol.4, No.2 : 602-612.

Sujarweni, V.W., (2014). Metodologi Penelitian. Pustaka Baru Press. Yogyakarta

Worung, V. S. T. (2016). Tenaga Kerja Wanita Bunga Potong di Kelurahan Kakaskasen II, Kecamatan Tomohon Utara, Kota Tomohon.Skripsi Fakultas Pertanian Universitas Sam Ratulangi Manado.

Zulfikri., Dolorosa E., \& Komariyati., (2014). Analisis Kontribusi Usaha Ternak Sapi Potong Terhadap Pendapatan Rumah Tangga Petani Di Kecamatan Tebas Kabupaten Sambas. Skripsi Fakultas Pertanian Universitas Tanjungpura. 